\title{
PENENTUAN KADAR LOGAM TIMBAL (Pb) AIR SUNGAI SINGINGI DI KABUPATEN KUANTAN SINGINGI RIAU Putri Ade Rahma Yulis ${ }^{\star 1}$, Desti ${ }^{2}$
}

\author{
Program Studi Pendidikan Kimia, FKIP Universitas Islam Riau \\ 2 Program Studi Pendidikan Biologi, FKIP Universitas Islam Riau \\ *Email: putriaderahmayulis@edu.uir.ac.id; ; Phone Number: +62853-1784-6217
}

\begin{abstract}
Abstrak
Ekosistem kita telah terkontaminasi oleh logam berat dengan konsentrasi yang tinggi yang dihasilkan oleh berbagai aktivitas manusia seperti kegiatan industri. Pada penelitian ini yang diuji adalah kandungan logam berat akibat aktivitas penambangan emas tanpa izin (PETI) di Sungai Singingi. Hal ini dilakukan berdasarkan fakta yang saat ini terjadi dimana keadaan sungai yang terus mengalami penurunan kualitas. Pemilihan penentuan kandungan logam berat $\mathrm{Pb}$ atau timbal karena kita ketahui pada pengolahan emas selain dipakai logam merkuri tetapi bersamaan digunakan timbal dan kadmium untuk mengikat emas. Ketiga logam merkuri, timbal dan cadmium digunakan untuk mengikat emas dan memisahkannya dari batuan dan tanah dalam bentuk sulfida. Metode penelitian ini menggunakan metode survei dengan penentuan titik sampling secara purposive berdasarkan lokasi maraknya aktivitas PETI. Sampel diukur pada empat titik dimulai dari titik yang paling dekat dengan aktivitas PETI hingga titik yang paling jauh dari aktivitas PETI. Adapun hasil pengujian untuk kadar logam timbal didapatkan hasil sebagai berikut ; $0,00382 \mathrm{mg} / \mathrm{L} ; 0,00165 \mathrm{mg} / \mathrm{L} ; 0,00124 \mathrm{mg} / \mathrm{L}$ dan $0,02525 \mathrm{mg} / \mathrm{L}$. Hasil yang didapatkan tersebut mengindikasikan bahwa sungai tersebut sudah terkontaminasi logam timbal meskipun jika dibandingkan dengan angka baku mutu logam berat di perairan maka kadar untuk logam berat timbal masih berada dalam ambang baku mutu yang diizinkan yakni sebesar 0,03 $\mathrm{mg} / \mathrm{L}$ untuk timbal.
\end{abstract}

Kata kunci : Aktivitas PETI, Pengukuran Logam Berat, Timbal (Pb), Sungai Singingi

Abstract

Heavy metal is the most hazardous of contaminats group. Our ecosystem has been contaminated by high concentrated of heavy metal that was generated from human activities such as industrial. On this research heavy metal content due to illegal gold mining (PETI) activities in Singingi river, Riau was measured. This was held because the river has degradation of its quality immediately. It was marked by high turbidity and declining of organism in that river. The choice of determining the content of heavy metal $\mathrm{Pb}$ or lead because we know that gold processing is not only used by mercury but also used by lead and cadmium to bind gold. The three metals are used to bind the gold and separate it from soil and stone in from sulfide.. This research used survey method with purposive sampling based on the rise location of PETI activities. Sample was measured at 4 point that started from the nearest and up to the furthest of PETI activities. The result of lead measurement was 0, $00382 \mathrm{mg} / \mathrm{L} ; 0,00165 \mathrm{mg} / \mathrm{L} ; 0,00124 \mathrm{mg} / \mathrm{L}$ and $0,02525 \mathrm{mg} / \mathrm{L}$, respectively. The results obtained indicate that the river has been contaminated with lead metal although if were compared with the quality standard of heavy metal in aquatic Lead still allowed with the number of quality standard for lead is $0,03 \mathrm{mg} / \mathrm{L}$.

Keywords : PETI activities, heavy metal measurement, Lead $(P b)$ Singingi river 


\section{Pendahuluan}

Indonesia mempunyai beragam ekosistem, namun banyak dari ekosistem tersebut tidak terjaga dengan baik atau dapat dikatakan dalam keadaan terkontaminasi. Salah satu kelompok kontaminan yang paling berbahaya adalah logam berat. Ekosistem kita telah terkontaminasi oleh logam berat dengan konsentrasi yang tinggi yang dihasilkan oleh berbagai aktivitas manusia seperti kegiatan industri, produksi energi, konstruksi, pengolahan limbah dan buangan kendaraan yang menyebabkan besarnya kontaminasi logam berat di atmosfer, air dan tanah (Bakırdere, S., Yaroğlu, T., Tırık, N., Demiröz, M., Fidan, A. K., Maruldalı, O., \& Karaca, 2013). Pencemaran akibat kegiatan industri dapat menyebabkan kerugian besar karena umumnya buangan atau limbah mengandung zat beracun antara lain raksa ( $\mathrm{Hg})$, Kadmium(Cd), Crom (Cr), Timbal ( $\mathrm{Pb})$ dan Tembaga $(\mathrm{Cu})$ yang sering digunakan dalam proses produksi suatu industri baik sebagai bahan baku, katalisator ataupun bahan utama. Logam-logam ini akan membentuk senyawa organik dan anorganik yang berperan dalam merusak kehidupan makhluk hidup (Arifin, 2012). Salah satunya operasional penambangan emas menggunakan air raksa $(\mathrm{Hg})$ sebagai media pengikat emas. Nantinya material yang dianggap sudah tidak mengandung emas tetapi masih mengandung merkuri oleh penambang akan dibuang begitu saja ke sungai. Selain logam merkuri, logam kadmium dan timbal juga dapat masuk kedalam perairan dalam bentuk limbah pertambangan bersama dengan merkuri yang digunakan untuk memisahkan emas dari batuan dan tanah dalam bentuk sulfida (Buyang, 2013).

Logam berat $\mathrm{Hg}, \mathrm{Cd}$ dan $\mathrm{Pb}$ disebut logam non esensial dan pada tingkat tertentu akan menjadi logam beracun bagi makhluk hidup (Mirdat, S., Pata'dungan, Y. S., \& Isrun, 2013). Oleh karena itu, perlu terus dilakukan penelitian dalam upaya penanganan limbah aktivitas PETI ini agar pencemaran lingkungan dapat ditanggulangi. Bagaimanakah kadar logam berat timbal sebagai pencemar di Sungai Singingi yang terdampak limbah aktivitas PETI di Kabupaten Kuansing belum pernah diteliti sebelumnya. Hasil penelitian yang diperoleh dapat memberikan informasi tentang kondisi air Sungai Singingi sehingga dapat digunakan sebagai bahan pertimbangan dalam penanganan limbah di Kabupaten Kuansing Provinsi Riau di masa yang akan datang. Hasil penelitian ini diharapkan dapat menyediakan kajian akademik tentang kualitas air sungai serta dapat dijadikan sebagai rujukan dalam perkuliahan. Oleh karena itu, telah dilakukan penelitian dengan judul "Penentuan Kadar Logam Timbal $(\mathrm{Pb})$ Air Sungai Singingi di Kabupaten Kuantan Singingi Riau". 


\section{Metode}

Penelitian ini dilaksanakan di Laboratorium Universitas Islam Riau Pekanbaru dan Laboratorium Balai Riset dan Standarisasi Industri Padang. Pengambilan limbah dilakukan di Sungai Singingi Kabupaten Kuantan Singingi Riau.Penelitian dilakukan pada tahun 2018.

Alat-alat yang digunakan dalam penelitian ini meliputi peralatan gelas digunakan di laboratorium (corong pemisah, gelas piala, gelas ukur, labu ukur, pipet ukur, pipet tetes,), Atomic Absorpstion Spectroscopy (AAS), hotplate. Bahan-bahan yang digunakan dalam penelitian ini adalah bahan kimia yang berkualitas pro-analisis antara lain : asam nitrat $\left(\mathrm{HNO}_{3}\right)$, Aquades. Logam berat timbal $(\mathrm{Pb})$ dianalisis menggunakan AAS (Atomic Absorption Spectroscopy) berdasarkan acuan SNI 6989-.8-2009

\section{Hasil dan Pembahasan}

Berdasarkan penelitian yang telah dilakukan di sungai Singingi tepatnya di Desa Koto Baru Kec. Singingi Hilir Kab. Kuansing mengenai uji kadar logam berat timbal (Pb). Diperoleh data-data sebagai berikut :

Tabel 1. Kadar Logam Timbal (Pb)

\begin{tabular}{cccc}
\hline No & \multicolumn{2}{c}{$\begin{array}{c}\text { Kadar Logam } \\
\text { Timbal (Pb) } \\
\text { rata-rata (mg/L) }\end{array}$} & $\begin{array}{c}\text { Standar Baku Mutu } \\
\text { Air Sungai } \\
\mathbf{~ m g / L ~}\end{array}$ \\
\hline 1 & Titik 1 & 0.00382 & 0.03 \\
\hline 2 & Titik 2 & 0.00165 & 0.03 \\
\hline 3 & Titik 3 & 0.00124 & 0.03 \\
\hline 4 & Titik 4 & 0.02525 & 0.03 \\
\hline 6 & & & \\
\hline 7 & & & \\
\hline
\end{tabular}

Data-data hasil pengukuran tersebut dilakukan di empat titik yaitu titik 1 ( merupakan titik terdekat dari aktivitas penambangan) yang berjarak $\pm 10 \mathrm{~m}$, kemudian di titik ke 2 dengan jarak $\pm 20 \mathrm{~m}$, titik ke 3 dengan jarak $\pm 30 \mathrm{~m}$ dan titik ke 4 (titik terjauh dari aktivitas penambangan dengan jarak $\pm 50 \mathrm{~m}$ ). Dari keempat titik pengambilan sampel air sungai tersebut, didapatkan konsentrasi logam dengan kadar yang berbedabeda. Adapun penelitian ini dilakukan dikarenakan masih aktifnya kegiatan Penambang Emas Tanpa Izin (PETI) di perairan tersebut. Hal ini tentunya akan berdampak buruk bagi keadaan perairan dan biota yang ada di perairan tersebut hingga akhirnya ke masyarakat sekitar lokasi tersebut. Kadar logam berat di lokasi tersebut perlu diuji karena pada umumnya para penambang illegal menggunakan unsur tersebut dalam proses pengolahannya. Seperti yang diungkapkan (Simange, S. M., Simbolon, D., \& 
Jusadi, 2010) bahwa proses penambangan dan ekstraksi emas biasa menggunakan zat kimia berbahaya seperti merkuri dan sianida. Selain itu logam berat kadmium dan timbal juga dapat masuk kedalam perairan dalam bentuk limbah pertambangan yang digunakan untuk memisahkan emas dari batuan dan tanah dalam bentuk sulfide (Buyang, 2013).

Pada penelitian ini yang diuji adalah kadar logam timbal, dikarenakan timbal merupakan salah satu logam berat yang termasuk kedalam kategori beracun. Selain itu beberapa proses penambangan emas juga menggunakan timbal secara bersama-sama dengan merkuri untuk memisahkan emas dari pengotornya. Perbedaan kadar logam timbal pada masing-masing titik dapat dilihat pada Gambar 1 dibawah ini :

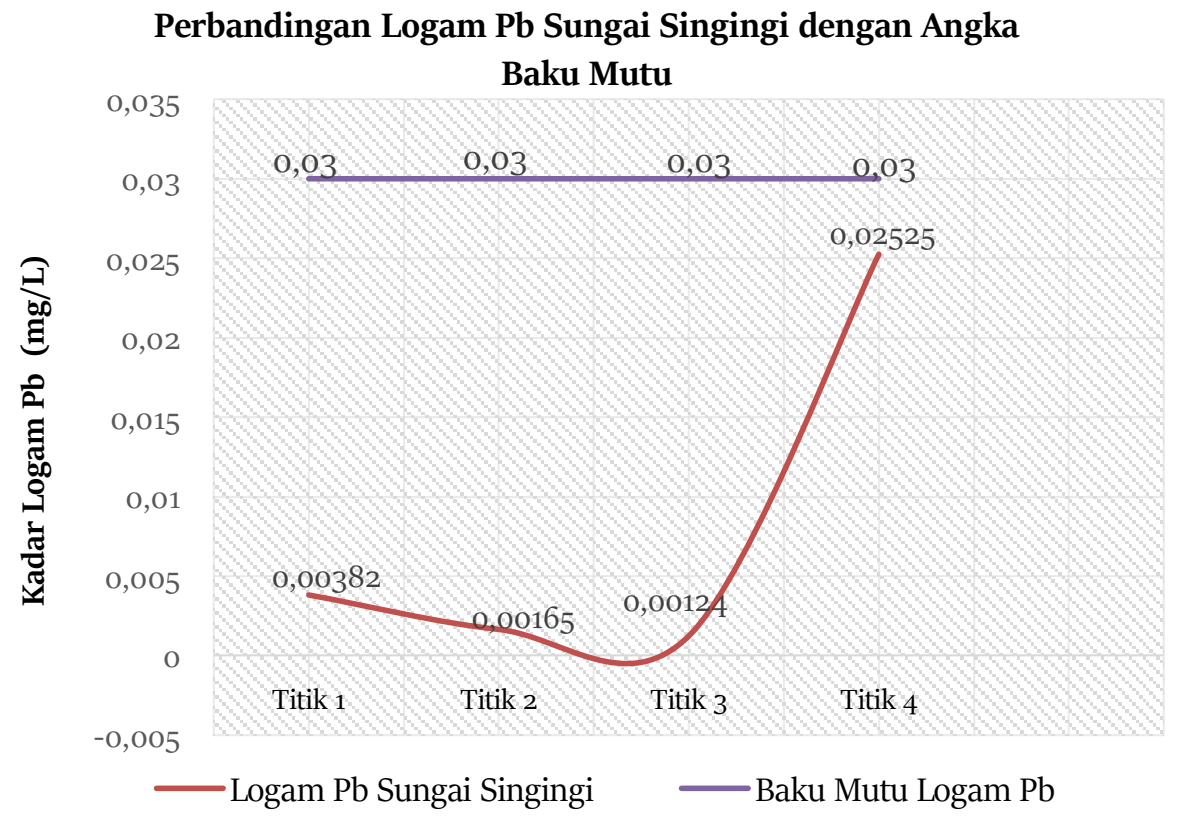

Gambar 1. Perbandingan Kadar Logam Pb Sungai Singingi dengan Angka Baku Mutu

Berdasarkan Gambar 1 dapat kita lihat bahwa logam timbal terdeteksi pada perairan tersebut. Adapun kadar masing-masing dari keempat titik pengukuran yaitu titik 1 sebesar 0,00382 mg/L, titik 2 sebesar 0,00165 mg/L, titik 3 sebesar 0,00124 $\mathrm{mg} / \mathrm{L}$ dan titik ke empat sebesar $0,02525 \mathrm{mg} / \mathrm{L}$. Dari hasil yang diperoleh dapat dilihat bahwa meskipun dalam jumlah kecil tetapi logam berat timbal terdeteksi di perairan merupakan suatu indikasi pencemaran karena timbal masuk kedalam golongan logam berat berbahaya dan beracun. Kadar logam timbal di keempat titik tersebut masih dalam ambang baku mutu perairan yang diizinkan sesuai PP No.82 Tahun 2001 yakni sebesar $0,03 \mathrm{mg} / \mathrm{L}$.

Lebih rendahnya kadar timbal yang terukur dibandingkan kadar logam merkuri karena memang pada proses pengolahan emas, hanya sebagian kecil penggunaan logam timbal bersamaan dengan cadmium. Dapat dilihat kadar logam timbal pada titik 
1,2, dan 3 tidak terlalu tinggi. Hal ini kemungkinan disebabkan selain jumlah limbah yang mengandung timbalnya hanya sedikit dan dapat pula dikarenakan logam sudah terbawa arah arus dan dapat pula disebabkan mengendapnya logam bersama lumpur didasar perairan. Hal ini sesuai dengan beberapa penelitian lainnya seperti (Buyang, 2013) yang mengungkapkan bahwa rendahnya kadar timbal di perairan dimungkinkan karena sebagian logam sudah terendapkan di dasar sungai dan sebagian lain sudah diserap oleh organisme yang ada di sungai. Kemudian menurut (Buyang, 2013) bahwa logam berat yang masuk kedalam sistem perairan, baik di sungai ataupun dilaut maka akan dipindahkan dari badan airnya dengan tiga proses yaitu ; pengendapan, adsorpsi dan absorpsi oleh organisme-organisme perairan. Hal ini juga sejalan dengan yang diungkapkan (Hutagalung, H. P., Setiapermana, D., \& Riyono, 1997) bahwa logam berat yang masuk kedalam lingkungan perairan akan lebih kecil kadarnya terdeteksi di air dibandingkan dengan didalam sedimen karena di perairan akan mengalami pengendapan, pengenceran,disperse dan penyerapan oleh organisme air, sehingga meskipun yang terukur dalam jumlah kecil belum bisa dipastikan perairan tersebut dalam keadaan aman, karena bisa jadi sudah banyak yang terakumulasi pada biota perairan tersebut.

Berdasarkan pengukuran kadar logam timbal tertinggi berada pada titik ke empat, meskipun lokasi ini merupakan lokasi terjauh dari aktivitas PETI. Hal ini dapat terjadi dikarenakan kadar logam tidak hanya berasal dari aktivitas PETI, namun dapat pula berasal dari akumulasi emisi gas buang kendaraan bermotor, serta limbah rumah tangga lainnya, dimana pada titik ini juga tidak jauh dari pemukiman warga yang dianggap sebagai baseline yang tidak tercemar dari aktivitas PETI. Selain itu logam timbal dapat pula berasal dari akumulasi kapal motor yang kebanyakan digunakan warga di daerah tersebut. Hal ini didukung pendapat (Connell, D. W., \& Miller, 1995) yang menungkapkan bahwa cairan limbah rumah tangga dan aliran air perkotaan cukup besar menyumbangkan logam $\mathrm{Pb}$ ke perairan. Hal senada juga diungkapkan (Pratama, A. G., Pribadi, R., \& Maslukah, 2012) bahwa kadar logam timbal di perairan dapat berasal dari polutan kendaraan bermotor, asap pabrik di sekitar perairan dan banyaknya aktivitas perahu di perairan tersebut.

Dilihat dari keseluruhan hasil pengukuran kadar timbal di sungai Singingi masih berada di ambang batas baku mutu yang diizinkan, namun tetap harus dilakukan upaya penanggulangan pencemaran agar tidak terjadinya kenaikan intensitas kadar logam timbal di lokasi tersebut. Hal ini cukup berbahaya mengingat dampak akumulasi timbal dalam tubuh manusia pada anak-anak akan menyebabkan gangguan petumbuhan fisik dan mental yang akan berakibat pada fungsi kecerdasan dan kemampuan akademik. Jika konsentrasi Timbal terus meningkat akan terjadi anemia dan kerusakan fungsi otak serta kegagalan fungsi ginjal (Nuraini, 2015) Dimana kita ketahui pula bahwa logam berat yang terdeteksi kecil di perairan belum menggambarkan kandungan logam berat secara keseluruhan, karena logam tersebut mudah terakumulasi didalam sedimen dan 
didalam organisme air, yang terakumulasi dalam tubuh organisme air yang secara tidak langsung akan berdampak pada masyarakat yang yang mengkonsumsi organisme air tersebut.

\section{Kesimpulan}

Dari hasil penelitian yang telah dilakukan didapatkan hasil pengujian untuk kadar logam timbal didapatkan hasil sebagai berikut; titik 1 sebesar $0,00382 \mathrm{mg} / \mathrm{L}$, titik 2 sebesar $0,00165 \mathrm{mg} / \mathrm{L}$, titik 3 sebesar $0,00124 \mathrm{mg} / \mathrm{L}$ dan titik ke empat sebesar $0,02525 \mathrm{mg} / \mathrm{L}$. Bila dibandingkan dengan angka baku mutu logam berat di perairan maka kadar logam berat timbal masih berada dalam ambang baku mutu yang diizinkan yakni sebesar $0,03 \mathrm{mg} / \mathrm{L}$. Dari hasil penentuan kadar logam berat ini sungai Singingi sudah masuk kedalam kategori tercemar untuk kandungan logam berat dan perlu dilakukan upaya-upaya penanggulangan agar keadaan tersebut segera teratasi sehingga kerusakan ekosistem dapat dikendalikan.

\section{Daftar Referensi}

Arifin, B. (2012). Analisis Kandungan Logam Cd, Cu, Cr Dan Pb Dalam Air Laut Di Sekitar Perairan Bungus Teluk Kabung Kota Padang. Jurnal Dampak, 9(2), 116122.

Bakırdere, S., Yaroğlu, T., Tırık, N., Demiröz, M., Fidan, A. K., Maruldalı, O., \& Karaca, A. (2013). Determination of $\mathrm{As}, \mathrm{Cd}$, and $\mathrm{Pb}$ in tap water and bottled water samples by using optimized GFAAS system with Pd-Mg and $\mathrm{Ni}$ as matrix modifiers. Journal of Spectroscopy.

Buyang, Y. (2013). Analisis Kadar Kadmium dan Timbal Pada Air di Lima Lokasi Sungai Totok Sulawesi Utara. Jurnal Agricola, Tahun III(No.1).

Connell, D. W., \& Miller, G. J. (1995). Kimia dan Eko-toksikologi Pencemaran.

Hutagalung, H. P., Setiapermana, D., \& Riyono, S. H. (1997). Metode analisis air laut, sedimen dan biota.

Mirdat, S., Pata'dungan, Y. S., \& Isrun, B. (2013). Status logam berat merkuri (Hg) dalam tanah pada kawasan pengolahan tambang emas di kelurahan Poboya, Kota Palu. AGROTEKBIS, 1(2).

Nuraini, I. S. (2015). Analisis Logam Berat Dalam Air Minum Isi Ulang (Amiu) Dengan Menggunakan Spektrofotometri Serapan Atom (SSA) Analysis Of The Levels Of 
Heavy Metal In Refill Using Atomic Absorption Spectrophotometry (AAS). Fis. Gravitasi, 14(37).

Pratama, A. G., Pribadi, R., \& Maslukah, L. (2012). Kandungan Logam Berat Pb dan Fe pada Air, Sedimen, dan Kerang Hijau (Perna viridis) Di Sungai Tapak kelurahan Tugurejo Kecamatan Tugu Kota Semarang. Journal of Marine Research, 1(1), 118122.

Simange, S. M., Simbolon, D., \& Jusadi, D. (2010). Analisis kandungan merkuri (HG) dan sianida $(C N)$ pada beberapa jenis ikan hasil tangkapan nelayan di Teluk Kao, Halmahera utara. 